\title{
Sporadic Creutzfeldt-Jakob Disease Presenting as Corticobasal Syndrome: A Rare Case
}

\author{
Kortikobazal Sendrom ile Prezente Olan Sporadik Creutzfeldt-Jakob Hastalığı: \\ Nadir Bir Olgu
}

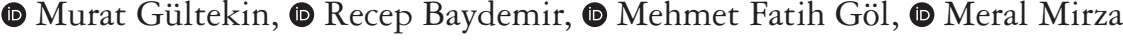 \\ Erciyes University Faculty of Medicine, Department of Neurology, Kayseri, Turkey
}

Keywords: Creutzfeldt-Jakob disease, corticobasal syndrome, Parkinson-Plus syndrome

Anahtar Kelimeler: Creutzfeldt-Jakob hastalığ1, kortikobazal sendrom, Parkinson Artı sendromu

\section{Dear Editor,}

A 56-year-old male was admitted to our neurosurgery polyclinic with clumsiness and weakness of his left arm. Diffusion-weighted magnetic resonance imaging (MRI) showed an infarction, and he was discharged with low-molecular-weight heparin. It was learned that he had new symptoms including desperation, reticence, slowness in motions, imbalance, being withdrawn, and forgetfulness, which initiated one month after his discharge.

Six months later, the patient was admitted to the neurology polyclinic because of worsening in his quality of life. His neurologic examination showed myoclonus, dysarthria, bilateral upper limb apraxia, alien hand phenomenon, bilateral rigidity, and bradykinesia predominantly affecting the left side. His mood was depressive. His mini mental state examination (MMSE) score was 16/30. An investigation for autoimmune markers and a paraneoplastic panel resulted negatively. An ophthalmologic examination was normal. Cranial MRI showed mild cortical atrophy. The patient was considered as having probable corticobasal syndrome, and L-dopa was initiated with a dose of $375 \mathrm{mg} /$ day.

At the 3-month follow-up, his symptoms worsened. Neurologic examination showed bilateral rigidity, bradykinesia, and apathy. His MMSE score was 10/30. FLAIR-weighted cranial MRI showed bilateral hyperintensity in the globus pallidus, putamen, and caudate nuclei. Diffusion-weighted images showed diffusion restriction in the bilateral caudate nuclei, putamen, and cortex, which was suggestive of "cortical ribbon" (Figure 1). These imaging features were suggestive of Creutzfeldt-Jakob disease
(CJD), and video electroencephalography (EEG) was performed. Video EEG showed periodic waves forming in a triphasic pattern, which occurred every 3-15 seconds, with a frequency of $1 \mathrm{~Hz}$, and are typical for CJD (Figure 2). No cells or microorganisms were detected in the cerebrospinal fluid (CSF). The CSF protein level was high $(61 \mathrm{mg} / \mathrm{dL})$. Paraneoplastic markers and limbic encephalitis panel, which were searched in the CSF, were negative. CSF 14-3-3 protein was not detected.

The "MRI-CJD Consortium" Criteria (2009) guide the diagnosis of sporadic CJD (1). Positive MRI findings are defined as an increased signal abnormality in nucleus caudatus and putamen or at least in 2 cortical areas (temporal-parietal-occipital) in diffusion or FLAIR-weighted images. Positive EEG findings are defined as periodic sharp wave complexes. Diffusion-weighted imaging should be added to cranial imaging in patients with a pre-diagnosis of CJD because it has high specificity and sensitivity (2).

Non-specific findings such as slowing in background activity may be observed in the acute period in EEG, but typical biphasic or triphasic periodic sharp wave discharges every $0.5-2$ seconds are observed as the disease progresses. If CJD is considered in diagnosis, EEG should be repeated.

Neuropathologic investigation is required for a definite diagnosis of CJD. For probable or possible diagnosis of CJD; rapidly progressive dementia with clinical findings (myoclonic jerks, pyramidal or extrapyramidal signs, akinesia or mutism) and auxiliary investigation tests (periodic triphasic waves in EEG, 143-3 protein positivity in CSF and "cortical ribbon" sign, increased

Address for Correspondence/Yazışma Adresi: Murat Gültekin MD, Erciyes University, Faculty of Medicine, Department of Neurology, Kayseri, Turkey Phone: +90 5058128292 E-mail: gultekin@erciyes.edu.tr ORCID ID: orcid.org/0000-0002-0609-4269

Received/Geliş Tarihi: 19.09.2017 Accepted/Kabul Tarihi: 05.12.2017

${ }^{\circ}$ Copyright 2018 by Turkish Neurological Society

Turkish Journal of Neurology published by Galenos Publishing House. 


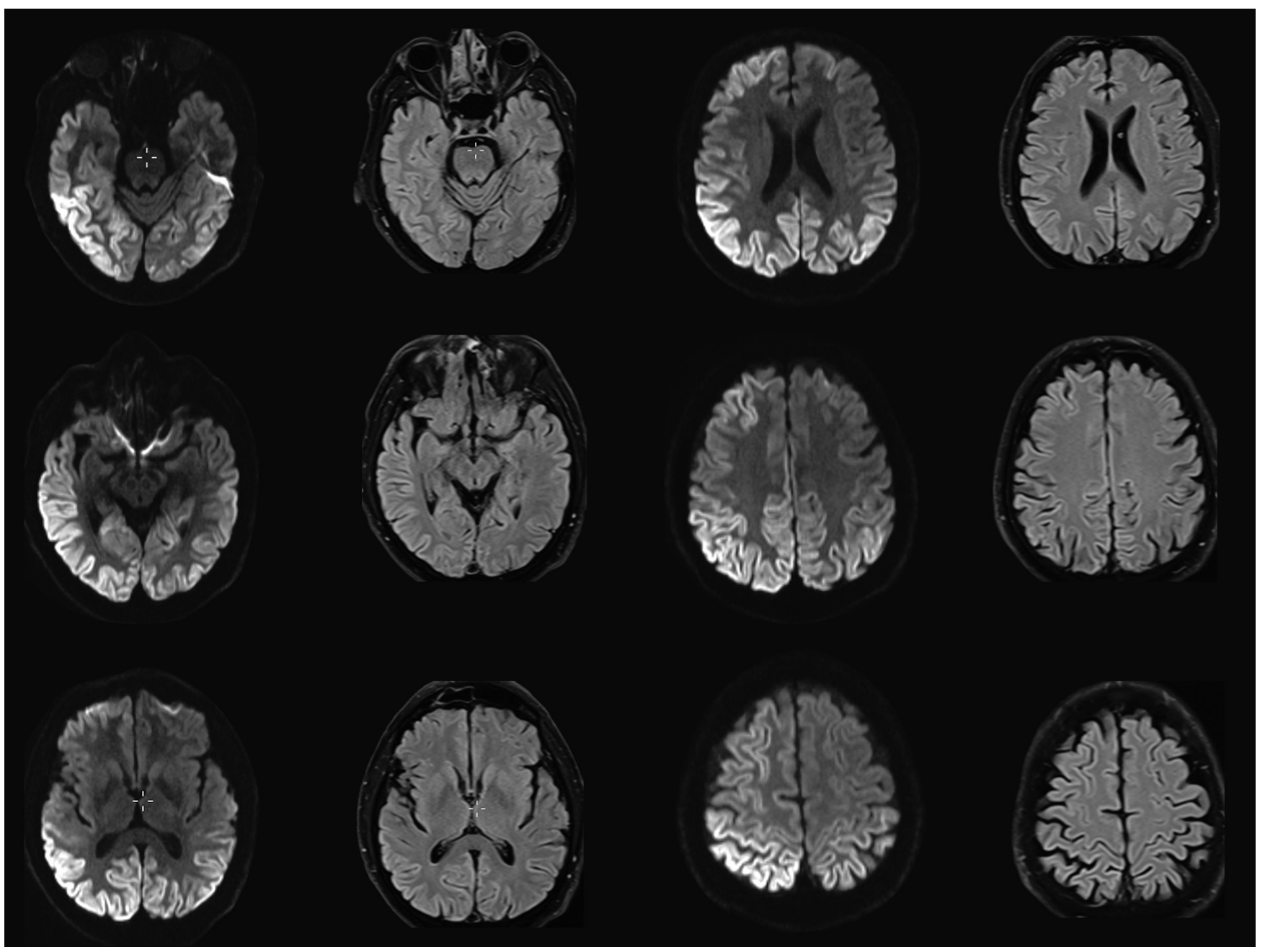

Figure 1. Bilateral cortical diffusion restriction (cortical ribbon) in diffusion-weighted imaging is shown here which is typical for Creutzfeldt-Jakob disease.

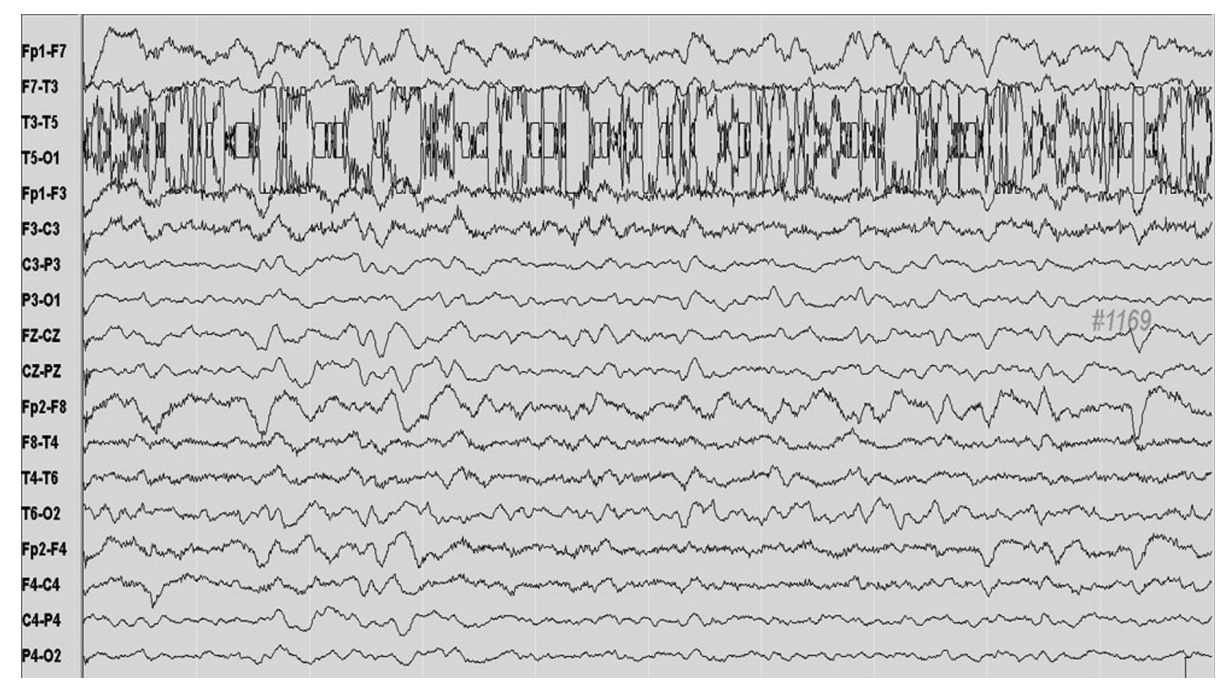

Figure 2. Triphasic periodic waves which occur every 3-15 seconds, have a frequency of $1 \mathrm{~Hz}$ and are typical for Creutzfeldt-Jakob disease are shown in this figure. This finding is suggestive of a slow virus infection such as Creutzfeldt-Jakob disease. 
hyperintensity in thalamus and basal ganglia in cranial MRI) are required (3).

Ethics

Informed Consent: Consent form was filled out by all participants.

Peer-review: Internally peer-reviewed.

Authorship Contributions

Concept: M.G., R.B., M.F.G., M.M., Design: M.G., R.B., M.F.G., M.M., Data Collection or Processing: M.G., M.F.G., Analysis or Interpretation: M.G., R.B., M.F.G., M.M., Literature Search: M.G., M.F.G., Writing: M.G., M.F.G.

Conflict of Interest: No conflict of interest was declared by the authors.
Financial Disclosure: The authors declared that this study received no financial support.

\section{References}

1. Zerr I, Kallenberg K, Summers D, Romero C, Taratuto A, Heinemann U, Breithaupt M, Varges D, Meissner B, Ladogana A. Updated clinical diagnostic criteria for sporadic Creutzfeldt-Jakob disease. Brain 2009;132:2659-2668.

2. Shiga Y, Miyazawa K, Sato S, Fukushima R, Shibuya S, Sato Y, Konno H, Doh-Ura K, Mugikura S, Tamura H. Diffusion-weighted MRI abnormalities as an early diagnostic marker for Creutzfeldt-Jakob disease. Neurology 2004;63:443-449.

3. Manix M, Kalakoti P, Henry M, Thakur J, Menger R, Guthikonda B, Nanda A. Creutzfeldt-Jakob disease: updated diagnostic criteria, treatment algorithm, and the utility of brain biopsy. Neurosurgical focus 2015;39:E2. 